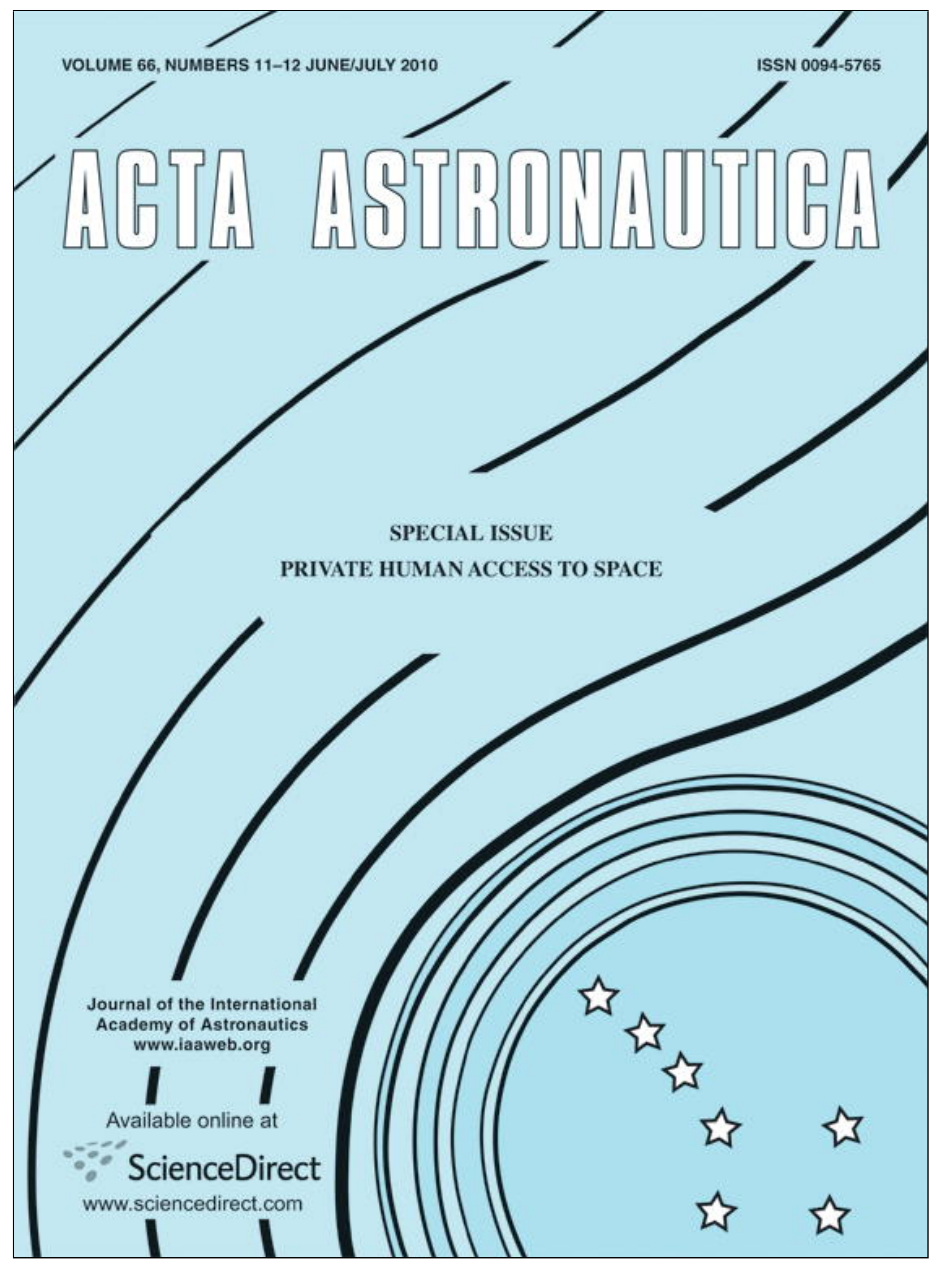

This article appeared in a journal published by Elsevier. The attached copy is furnished to the author for internal non-commercial research and education use, including for instruction at the authors institution and sharing with colleagues.

Other uses, including reproduction and distribution, or selling or licensing copies, or posting to personal, institutional or third party websites are prohibited.

In most cases authors are permitted to post their version of the article (e.g. in Word or Tex form) to their personal website or institutional repository. Authors requiring further information regarding Elsevier's archiving and manuscript policies are encouraged to visit:

http://www.elsevier.com/copyright 


\title{
Promising roadmap alternatives for the SpaceLiner
}

\author{
Martin Sippel * \\ Space Launcher System Analysis (SART), DLR, Bremen, Germany
}

\section{A R T I C L E I N F O}

\section{Article history:}

Received 10 June 2009

Received in revised form

13 January 2010

Accepted 19 January 2010

Available online 9 February 2010

\section{Keywords:}

Space-tourism roadmap

RLV

SpaceLiner

\begin{abstract}
A B S T R A C T
The paper describes the vision and potential roadmap alternatives of an ultrafast intercontinental passenger transport based on a rocket powered two-stage reusable vehicle. An operational scenario and the latest technical lay-out of the configuration's preliminary design including flight performance are described. The question of how the revolutionary ultrafast transport can be realized is addressed by an assessment of the different technological and programmatic roadmap alternatives.
\end{abstract}

(c) 2010 Elsevier Ltd. All rights reserved.

\section{Introduction}

A strategic vision has been proposed by DLR which ultimately has the potential to enable sustainable low-cost space transportation to orbit. The baseline idea is simple and quite conventional: strongly surging the number of launches per year and hence dramatically shrinking manufacturing and operating cost of launcher hardware.

The obvious challenge of the vision is to identify the very application creating this new, large-size market. All recent assessments of the launch business are sobering. The required new market must be significantly different from today's orbiting of communication or earth observation satellites because almost no growth is to be expected in these areas. As has been demonstrated by the ASCENT study [2] for NASA MSFC, "most of today's markets, both commercial and governmental, are virtually unaffected by even massive reductions in launch prices". The ASCENT study prognosis of an almost flat launch demand in the next 15-20 years contains already some optimism of new emerging applications. Without the launch demand generated by new businesses there would be a rather rapid decline of the launch industry during the forecast period.

\footnotetext{
* Tel.: +49421 24420145; fax: +4942124420150.

E-mail address: Martin.Sippel@dlr.de
}

Nevertheless a market, well beyond the recent assessment, could be created if the conventional thinking of what rocket propelled vehicles are to be used for is exceeded.

Ultrafast transportation, much faster than supersonic and even potential hypersonic airplanes, is definitely a fundamental new application for launch vehicles. Even in the case that only a very small portion of the upper business travel segment could be tapped by a rocketpropelled intercontinental passenger transport, the resulting launch rates per year would be far in excess of any other credible scenario (Fig. 1 ). By no more than partially tapping the huge intercontinental travel and tourist market, production rates of RLVs and their rocket engines could increase hundredfold which is out of reach for all other known earth-orbit space transportation applications. The fast intercontinental travel form of space tourism, not only attracting the leisure market, would, as a byproduct, enable to also considerably reduce the cost of space transportation to orbit.

\section{Background and analysis of current situation}

Currently, the worldwide launcher sector including research and industry is running into a deep crisis. 


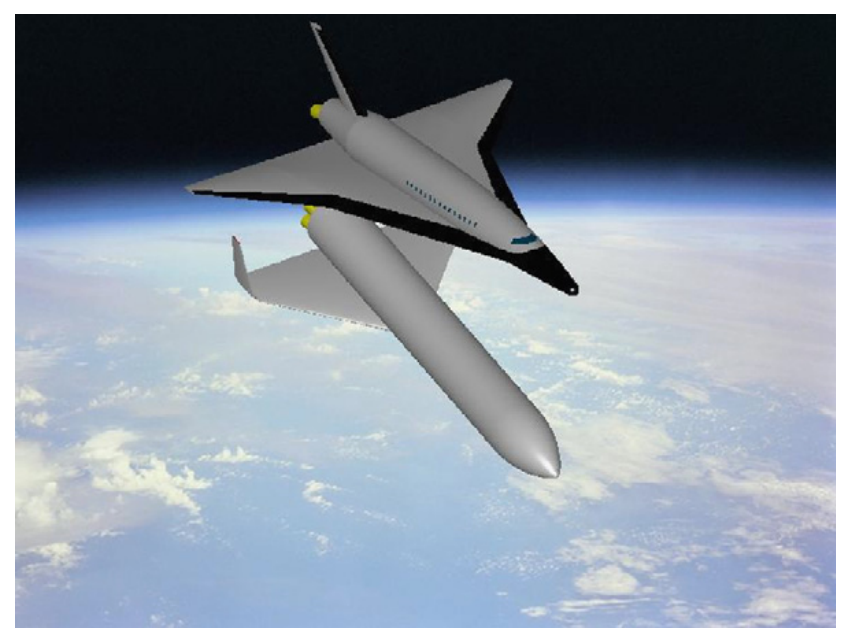

Fig. 1. The SpaceLiner vision of a rocket-propelled intercontinental passenger transport, shown here in an artist's impression of its first configuration from 2005, could push spaceflight further than any other credible scenario.

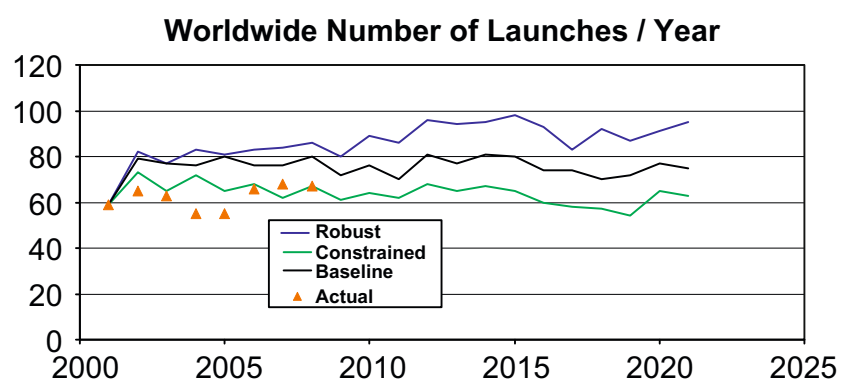

Fig. 2. Baseline, robust and constrained forecasts of worldwide number of launches per year for different ASCENT study [2] scenarios compared with actual number of launches.

A recent assessment of the launch business already including some kind of optimism is sobering. The Futron Analysis of Space Concepts Enabled by New Transportation (ASCENT) study [2] was an undertaking of NASA Marshall Space Flight Center (MSFC) and Futron Corporation designed to provide the best possible estimates of global launch vehicle demand for the next 20 years via the research, analysis and forecasting of current, and future space markets and applications. The ASCENT study prognosis of an almost flat launch demand in the next 15-20 years (Fig. 2) contains already new emerging applications. Without the launch demand generated by these new businesses (particularly public space travel) there would be a rather rapid decline of the launch industry during the forecast period.

Fig. 2 shows that even the most optimistic "robust" scenario would only see a slight increase in the number of launches until 2021. The recent history of the past few years sadly demonstrated that the "constrained" lower end of the prognosis was still too optimistic. The actual number of launch attempts to orbit in every year up to 2006 remained beneath even the most pessimistic prognosis as shown in Fig. 2. In 2007, for the first time, the "constrained" curve has been slightly exceeded but still remaining notably below the forecasted "baseline".
The consequences for the development and operation for all kinds of launchers are catastrophic. The ruinous competition on the shrinking commercial telecommunication market requires heavy subsidies only for continuing the operation of existing launchers. On the launcher development side the situation is even worse: The very small market volume and the underutilization of existing infrastructure do not require any new large development project. Everything needed could be served by the available, sometimes 50 years old rocket designs. Technological progress is slowing or stopping because of the decline in development budgets. Without fascinating and challenging tasks a "brain-drain" of the best and brightest engineers and scientists seems to be inevitable in the near future.

If one postulates that a surge in launches requires a dramatic reduction in launch prices and vice versa, the perspective is quite desperate. The required new market must be significantly different from today's orbiting of communication or earth observation satellites because almost no growth is to be expected in these areas. As has been demonstrated by the ASCENT study, "most of today's markets, both commercial and governmental, are virtually unaffected by even massive reductions in launch prices." [2].

Fortunately, the idea for a new application of spaceflight is gaining momentum: The space tourism market.

A number of initiatives on commercial space flight have been recently started with companies developing privately funded crew vehicles and launchers. For human space flight, this phenomenon was initially triggered by the Ansari X Prize, a contest focused on suborbital crew vehicles for space tourism. The Ansari X Prize was won in October 2004 when a privately funded crew vehicle, SpaceShipOne developed by Scaled Composites, reached an altitude of $111 \mathrm{~km}$. Presently, a number of privately funded companies are completing the development of suborbital vehicles. Check for a brief overview on these activities in Ref. [7].

Although, what is called "suborbital space travel" is assessed as an additional promising market, Futron's forecast for suborbital space travel outside of the ASCENT analysis is relatively limited with annual revenues about US\$ 700 million [1]. However, despite all achievements and promising developments, one has to realize that the overall impact of all recent developments in space travel on the launch industry and its technology is limited at best. The "low-tech" approach seems to be the only affordable one for small and medium private companies in the near-term. As a result, it is unlikely that the necessary advancement in launch vehicle technology is notably assisted. Further, the overall emerging market volume is insufficient to significantly support the classical rocket launch business. The question comes up if a business could be conceived which significantly raises the number of launches exceeding all current prognoses and hence reduces costs.

Ultralong distance travel from one major business center of the world to another major agglomeration on earth is a huge and mature market. Since the termination of Concorde operation, intercontinental travel is restricted 
to low-speed, subsonic, elongated multi-hour flight. An interesting alternative to airbreathing hypersonic passenger airliners in the field of future high-speed intercontinental passenger transport vehicles might be a rocket-propelled, suborbital craft. Such a new kind of "space tourism" based on a two stage RLV has been proposed by DLR under the name SpaceLiner [3] (Fig. 1). Ultralong-haul distances like Europe-Australia could be flown in $90 \mathrm{~min}$. Another interesting intercontinental destination between Europe and North-West America could be reduced to flight times of about $1 \mathrm{~h}$.

Ultrafast transportation far in excess of supersonic and even potential hypersonic airplanes is definitely a fundamental new application for launch vehicles. Even in the case that only a very small portion of the upper business travel segment could be tapped by a rocket-propelled intercontinental passenger transport, the resulting launch rates per year would be far in excess of any other credible scenario. By no more than partially tapping the huge intercontinental travel and tourist market, production rates of RLVs and their rocket engines could increase hundredfold which is out of reach for all other known earth-orbit space transportation. The fast intercontinental travel space tourism, not only attracting the leisure market, would, as a byproduct, also enable to considerably reduce the cost of space transportation to orbit.

A first assessment of the SpaceLiner's potential business case is described in Refs. [3,4,7]. The total development cost and investment into the infrastructure will be huge. The passenger spaceflight business might nevertheless be able to generate a yearly profit, even if the investment is to be privately financed [7] and the operation is tapping no more than a small fraction of the upper intercontinental travel segment.

Surely it is to be acknowledged that these are preliminary estimations with a lot of uncertainties. Studies on improved assessments have been initiated. One of the main reservations is if there will be sufficiently enough people willing to pay a significant extra fee per flight. This question might be answered with increased confidence if commercial space flight ventures will become a reality. Such a precursor application allows testing the market and gaining operational experience.

\section{Mission and operational scenario of the SpaceLiner}

Since the demise of Concorde operation, intercontinental travel is restricted to low-speed, subsonic, elongated multi-hour flight. The reasons for the commercial failures of Concorde and its Soviet counterpart Tu-144 can be seen in their relatively high cost but severely restricted range offering only a limited benefit for travelers. However, the public interest in hypersonic passenger airliners is still alive.

Conventional wisdom always assumes to operate these transport craft, depending on the flight Mach-number, by combined airbreathing turbo-jet-RAM-, or SCRAMengines. Although these propulsion systems seem to be feasible in principle, their utilization is still quite far away in the future due to technical challenges, development, and operational cost. The technical demonstration of SCRAM has reached the subscale level at best. The airbreathing vehicles are very sensitive to their achievable range and to environmental issues. Therefore, they might be severely restricted in the destinations they are able to actually serve. The potential RBCC/SCRAM propulsion of hypersonic aircraft has a low technology readiness level and the technical feasibility of such a large-scale propulsion system raises tremendous design challenges and is yet to be demonstrated [5].

An interesting alternative in the field of high-speed intercontinental passenger transport vehicles might be a rocket-propelled, suborbital craft. The functionality of rocket propulsion is a proven technology since decades and their performance characteristics are well known. Furthermore, a rocket powered RLV-concept like the SpaceLiner is more attractive because the flight durations are two to three times lower than those of even the most advanced airbreathing systems. In contrast to the first generation of SST, a substantial advantage in travel times and hence improved business case can be expected.

The negative environmental impact of the LOX-LH2 propelled SpaceLiner seems to be much less critical than for airbreathing concepts. The engines do not pollute the atmosphere with nitrogen oxides because they do not use the air. However, the greenhouse gas effect of the unavoidable water vapor at high altitudes is to be evaluated in future analyses with suitable climate models. Most of the flight trajectory is at a much higher altitude than for the airbreathing vehicles considerably reducing the noise impact on ground. Nevertheless, the launch has to most likely be performed off-shore because usually no remote, unpopulated areas are found close to the business centers of the world. Consequently decoupling of the launch and landing site will create some logistical challenges. A first assessment of the logistics is described in [9].

Interesting intercontinental flight routes from one major business center of the world to another major agglomeration are shown in Fig. 3. Note that the shown destinations and tracks are neither fixed nor exhaustive. Changes or additional sites on other continents could be considered.

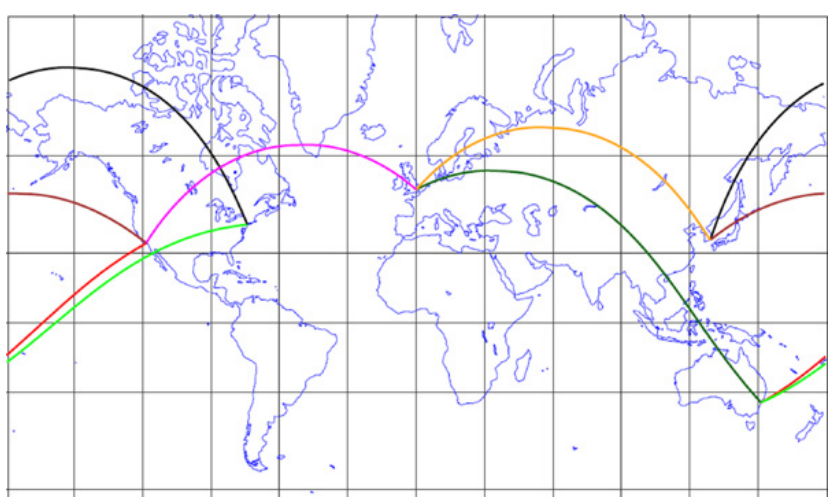

Fig. 3. An intercontinental ultrafast travel network could be established by the Spaceliner concept connecting some of the main population and business areas. 
The largest benefits of the SpaceLiner ultrafast transport could be gained on the ultralong-haul routes. Thus, a trans-Atlantic flight has not been considered in the preliminary mission definition. Potentially interesting destinations and their respective flight distances following the orthodrome are listed in Table 1. The baseline mission scenario assumes over-flying populated areas at high altitudes by the RLV during the ascent phase. Restrictions in the flight azimuth could force other routes which will be investigated in the future. This might include more polar flights and utilization of the passenger stage's crossrange capability.

Travel times of any airliner are not identical to flight times. Additional times for commuting to the airport hub which offers the long-distance flight, check-in, securitycheck and those to be accounted for waiting and transfer are to be considered. In a reasonable assumption the commuting time will increase in case of the SpaceLiner travel due to the limited number of launch sites. Ref. [9] mentions some options on how to address this challenge. A preliminary estimation of the expected travel time for a SpaceLiner passenger shows approximately 5-6h for ultra-long distances. This result corresponds to a reduction in the actual time needed for travelling between at least $75 \%$ and $80 \%$ compared to conventional subsonic airliner operation: About $23 \mathrm{~h}$ for non-stop service and

Table 1

Characteristic distances of some potential SpaceLiner missions.

\begin{tabular}{lc}
\hline Route & $\begin{array}{l}\text { Approx. } \\
\text { distance (km) }\end{array}$ \\
\hline Western Europe-South-East Australia & 17000 \\
Western Europe-South-East Asia & 9200 \\
Western Europe-North-West America & 8800 \\
South-East Australia-North-East America & 16100 \\
South-East Australia-North-West America & 12100 \\
South-East Asia-North-East America & 11300 \\
South-East Asia-North-West America & 9600 \\
\hline
\end{tabular}

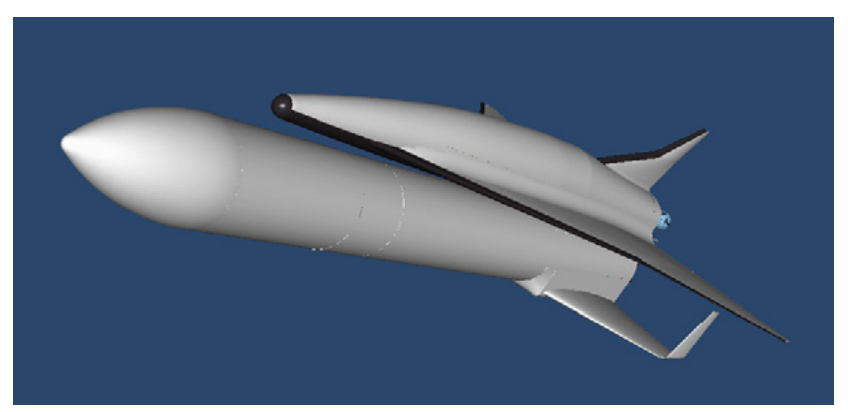

Fig. 4. Latest geometry of generic rocket powered intercontinental passenger spaceplane SpaceLiner (top) with reusable booster (bottom). typically about $30 \mathrm{~h}$ for single stop Europe-Australia flights.

\section{Technical development status}

First proposed in 2005 [3], the SpaceLiner is under constant development and a first major update has been recently published [8].

This "first generation" design has subsequently been used for more detailed studies, especially in the fields of trajectory simulations, aerothermodynamics, and for defining the requirements for the active cooling system. One of the most important results is a first engineering estimation on the amount of cooling fluid required during skip and glide reentry after the orbiter's MECO $[6,8]$.

All engines should work from lift-off until MECO. A propellant crossfeed from the booster to the orbiter is foreseen up to separation to reduce the overall size of the orbiter stage. During the SpaceLiner's design evolution the expansion ratios of the booster and orbiter engines are adapted to their respective optimums, while mass flow, turbo-machinery, and combustion chamber remain identical. Fuel rich staged combustion cycle engines with a moderate $16 \mathrm{MPa}$ chamber pressure, $384.5 \mathrm{~kg} / \mathrm{s}$ mass flow, and $437.6 \mathrm{~s}$ (booster)/448 s (orbiter) $I_{\mathrm{sp}}$ in vacuum are assumed for the propulsion system. These engine performance data are not overly ambitious and have already been exceeded by existing engines like SSME or RD-0120. However, the ambitious goal of a passenger rocket is to considerably enhance reliability and reusability of the engines beyond the current state of the art.

An optimum configuration of minimum total size and mass has been iterated based on preliminary subsystem sizing and trajectory analyses of the ambitious AustraliaEurope reference design mission. See Fig. 4 for the resulting launch configuration including booster.

The booster is a large unmanned tank structure providing thrust and propellant crossfeed to the orbiter up to staging. Its total propellant loading including residuals reaches $760 \mathrm{Mg}, 105 \%$ of the space shuttle external tank. Compare the latest characteristic SpaceLiner data in Table 2.

The orbiter, designed to transport 50 passengers with their luggage, accommodates no more than $155 \mathrm{Mg}$ propellant in the aft section which is designed as an aeroshell-like concept. Aerodynamic considerations and severe thermal conditions in the atmospheric skipping phase exclude any integral tank structure. The orbiter's structural index is at $60 \%$, relatively conservative for a large cryogenic RLV. However, it has to be considered that the vehicle has to include a passenger cabin and safety features. The combined dry mass of both SpaceLiner

Table 2

SpaceLiner2 characteristic vehicle data (reference mission).

\begin{tabular}{|c|c|c|c|c|c|c|c|}
\hline & $\begin{array}{l}\text { GLOW mass } \\
(\mathrm{kg})\end{array}$ & $\begin{array}{l}\text { Mass at } \\
\text { burnout }(\mathrm{kg})\end{array}$ & $\begin{array}{l}\text { Nominal ascent } \\
\text { propellant mass }(\mathrm{kg})\end{array}$ & Total length (m) & $\begin{array}{l}\text { Max. fuselage } \\
\text { diameter }(\mathrm{m})\end{array}$ & Wing span (m) & $\begin{array}{l}\text { Projected wing } \\
\text { surface area }\left(\mathrm{m}^{2}\right)\end{array}$ \\
\hline Orbiter & 277900 & 122900 & 155000 & 60.4 & 6 & 40 & 955 \\
\hline Booster & 870950 & 116950 & 754000 & 73.4 & 7 & 25.5 & 325 \\
\hline
\end{tabular}


stages is estimated at $212 \mathrm{Mg}$. Total take-off mass of the latest SpaceLiner2 is about $1150 \mathrm{Mg}$ [8].

The Australia-Europe mission is one of the technically most challenging distances with significant passenger volume. However, several northern hemisphere flights like trans-Pacific or trans-Atlantic are less challenging (compare Table 1) but offer a larger market potential. Thus, the flight from Europe to the west coast of North America, with a minimum orthodrome distance around $9000 \mathrm{~km}$, has been investigated for its suitability with the SpaceLiner2 configuration [8]. As has been found an elongated orbiter derivative could transport 100 passengers about $9000 \mathrm{~km}$ in $1 \mathrm{~h}$.

\section{Development roadmap assessment}

The question of how the revolutionary ultrafast transport SpaceLiner can best be realized does not only depend on the principle technical feasibility of the concept. The latter might be sufficient in a fully government funded initiative. However, the sheer size of the endeavor [7], which might come close to project Apollo, makes such an approach unlikely. Moreover, it would be questionable enabling a small group of very rich people a prestigious ultrafast trip around the world and through space with development paid by the large majority who cannot afford this form of travel. An even more fundamental requirement is the acceptability by the passengers because no astronauts could be instructed to take the risk of flying.

Therefore, it is quite appropriate to early identify all possible development roadmaps which are compatible with current trends in aeronautics and spaceflight and subsequently make an assessment which of those is the most promising one. Evaluation criteria are development sense for establishment of the required technologies, public acceptability of the operation, potential synergies in infrastructure, and very important the affordability of the largely to be privately funded initiative.

The following six generic development roadmaps until introduction of the SpaceLiner operations are investigated:

- Evolutionary aeronautical: Starting from today's subsonic airliners the worldwide net of air travel is evolved following an incremental increase in flight velocity. Initiated by new generations of increasingly larger supersonic aircraft, followed by hydrogen based hypersonic airliners. Once such a market would have been established, the development of the much faster rocket-based SpaceLiner technology could be kicked off.

- Evolutionary launcher through full RLV: Developing a large fully reusable launch vehicle and operating this space transportation system for payload delivery to orbit. After introduction of a space shuttle like manned orbiter the SpaceLiner configuration is eventually developed.

- Manned crew flight with expanding exploration: Currently, the official trend in the US space program proposes expanding manned spaceflight beyond LEO and extending flights to the Moon and later Mars. Such endeavors would require a sophisticated launcher infrastructure including super-heavy vehicles, like the envisioned Ares V. Astronauts will be launched inside non-winged, conventional capsules with a 1960s heritage.

- Ultrafast cargo transport: Establishing an ultrafast intercontinental parcel service for high value, urgent goods or document delivery. This transport could be based in an early stage on small expendable vehicles with reentry capsules, would evolve to winged, reusable reentry stages, and eventually will reach the ultrafast passenger transport SpaceLiner.

- Space-tourism: The idea of the so-called suborbital space-tourism has gained momentum recently. A common characteristic of the considerable number of groups and companies working on these types of vehicles is that they are all privately funded. Their goal of reaching an altitude of about $100 \mathrm{~km}$ in a ballistic trajectory can be achieved by less demanding technology than conventional spaceflight because the energy requirement is much lower. The interest on the passengers' side is already quite high before the first vehicle has performed its test flight and numerous people are willing to pay a significant amount for being on top of the waiting list.

- Military application: The military and its requirements have been playing a prominent role in innovative aerospace developments for a long time. Today's intercontinental ballistic missiles are quite close in their basic idea to an ultrafast rocket propelled vehicle as the SpaceLiner concept. However, a vehicle with benign final approach velocities like the SpaceLiner requires different applications than the dispensing of warheads. The former could be similar to the ultrafast cargo delivery scenario but could also include deployment of special forces and troops in urgent military missions. At a later stage this technology could be transferred to civil passenger transports as happened several times in the past.

Obviously, unlimited combinations between the above listed scenarios can be imagined. This description should be understood as archetypical representations of certain development directions.

These six development roadmaps are preliminarily assessed as follows:

- Evolutionary aeronautical: The major drawback of this scenario is the fact that the required technologies for efficient supersonic and hypersonic propulsion are much different to the requirements of the SpaceLiner. On a first look the incremental change in passenger transport might be an advantage for operational acceptability. However, as the infrastructure needs strongly differ and potentially a certain step like large hypersonic SCRAM might never be reachable, this roadmap does not look very promising. In any case the introduction of the SpaceLiner would be postponed by decades and overall development cost would be skyrocketing. 


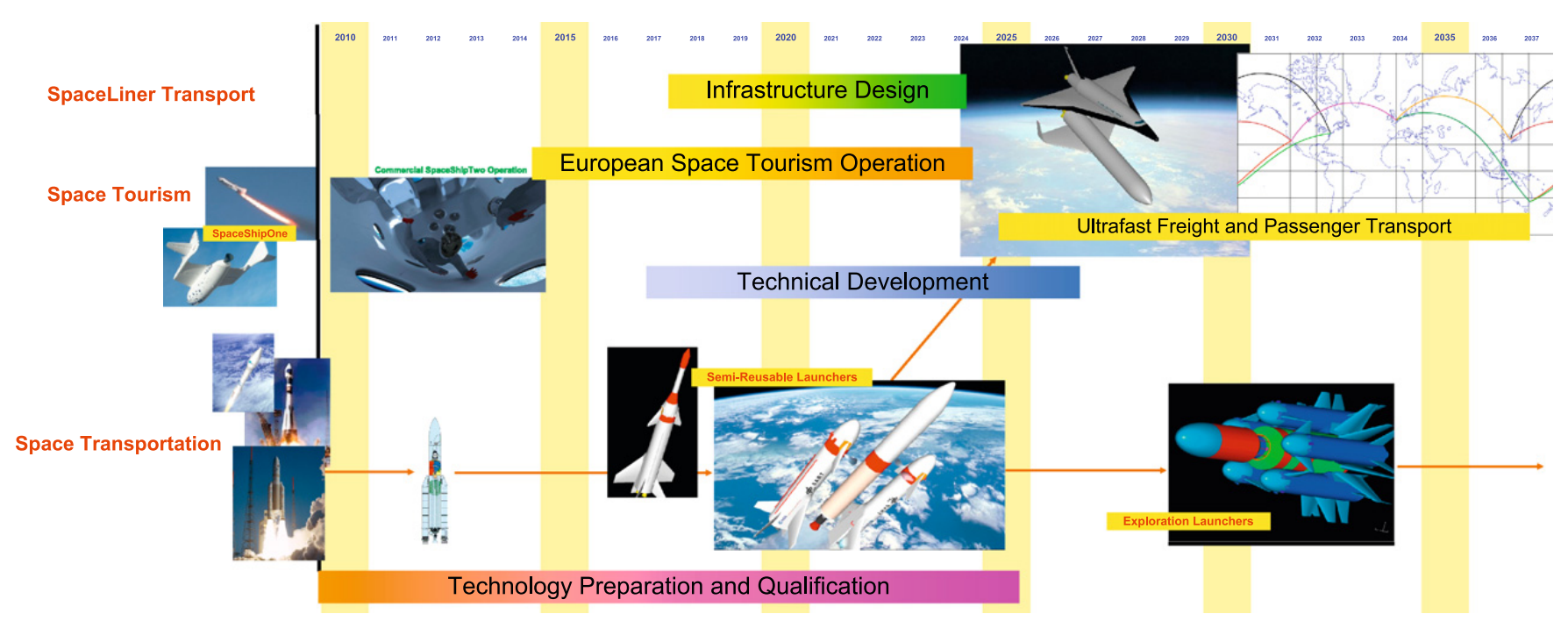

Fig. 5. Proposed roadmap of SpaceLiner development and operation.

- Evolutionary launcher through full RLV: The required technologies for RLVs as reusable engines, cryogenic tanks, and thermal insulation are very similar to those of the SpaceLiner. Requirements on turn-around times are similar but probably less stringent. The major problem is to find the real need justifying development of a full RLV in the current launcher market situation. In order to come out of this situation exactly the inverse idea of pushing spaceflight by introduction of a rocket-propelled ultrafast passenger transport is proposed in Section 2. Nevertheless, the operational experience of a semi-reusable launcher like LFBB could be very helpful and still be affordable.

- Manned crew flight with expanding exploration: Technology synergies are limited to the rescue system of the SpaceLiner. An expanding space engineering infrastructure would definitely support any development approach but the operational experiences gained will be limited.

- Ultrafast cargo transport: The major interest of this scenario is found in the much lower safety requirements for cargo than for people, which would allow testing the technologies and operations at lower cost. Such shipping might already be done today with old ballistic missiles but is currently not possible because of the risk of being confused with military strikes. This problem could also become relevant for the SpaceLiner's operation and is to be addressed by international treaties and by an international suborbital flight control authority. The market potential of ultrafast cargo delivery is difficult to estimate. The need of fast original document transportation at former times might loose its appeal because of safe electronic transmission procedures. However, the rapid delivery worldwide of organ transplants can be imagined as an interesting application.

- Space-tourism: Any type of an expanding and commercially successful suborbital space-tourism would be an enormous support for finding investors for the technologically far more demanding SpaceLiner concept. At least some kind of ground infrastructure and flight traffic control might be operationally tested. The continuous use of this infrastructure with their related launch sites by an ultrafast transport is questionable, but should not be excluded. The required technologies for suborbital space-tourism vehicles, however, can support only on a strictly limited basis the much more ambitious and sophisticated skills necessary for the SpaceLiner.

- Military application: In case a major interest on such a configuration would actually exist for the armed forces, development funding will not be a problem. Then, however, it is likely that civil use of the technology will be blocked for quite some time. The benefit of an ultrafast cargo and soldier transport for military tactical operation is not obvious. The dispensing of warheads evidently does not require any kind of reusable vehicle. From a programmatic point of view the military involvement is not attractive because in any case the total number of potential uses of the system is very much limited. This is contrary to the interest of surging production rates of launch vehicles to cut cost. Thus, it looks as if the military has already played its role in the past but cannot significantly contribute in bringing forward the SpaceLiner concept.

A preliminary roadmap has been established by summarizing the assessments of the above scenarios. The three roadmaps of aeronautical evolution, manned flight and exploration, and military are of minor relevance. A combination of the other three seems to be more promising. Fig. 5 depicts this roadmap over a span of more than 25 years.

\section{Conclusion}

Simulations show that an ultrafast rocket-propelled intercontinental passenger transport could one day flexibly serve the different passenger volumes on the major business routes of the world. The SpaceLiner 
concept, explicitly defined for this purpose, requires challenging technology but avoids any exotic equipment. Its size and performance are intentionally less demanding than well known Space Shuttle technology which is now more than 25 years old. However, some key technologies have to be improved, to make the SpaceLiner vision viable. The most important are:

- High reliability and safety.

- Long life staged combustion cycle rocket engines.

- Transpiration cooling to safely withstand a challenging aerothermal environment.

- Fast turn-around times currently unknown in the launcher business.

Increasing the TRL of advanced technologies like transpiration cooling, reusable cryogenic thermal insulation or advanced GNC is indispensable for any realization of the Spaceliner vision. Intensive technology development has to start soon for enabling the introduction of high speed freight and passenger service before 2030.

Six different generic development roadmaps of the Spaceliner are investigated: Evolutionary launcher, RLV, manned crew exploration, cargo transport, space-tourism, and military applications. A combination of the three roadmaps RLV, space-tourism, and cargo transport is assessed as the most promising approach. Typical RLVtechnologies of a potential semi-reusable, unmanned next generation launcher and the experience gained with such an RLV would benefit the operational introduction of the SpaceLiner. The market can be tested and developed by all forms of early suborbital space-tourism and investor's confidence could be achieved. The latter aspect is important because while technologies should be funded by the public, the vehicle development and infrastructure is to be privately financed. The considerably lower safety requirements for cargo than for people transport would allow testing the SpaceLiner's technologies and operations at lower cost before initiating the final goal of passenger flight through space.

\section{References}

[1] S. Beard, J. Starzyk, Space tourism market study—orbital space travel \& destinations with suborbital space travel, Futron, October 2002.

[2] Analysis of space concepts enabled by new transportation (ASCENT study), Futron, January 2003.

[3] M. Sippel, J. Klevanski, J. Steelant, Comparative study on options for high-speed intercontinental passenger transports: air-breathing-vs. rocket-propelled, IAC-05-D2.4.09, October 2005

[4] M. Sippel, J. Klevanski, A. van Foreest, A. Gülhan, B. Esser, M. Kuhn, The SpaceLiner concept and its aerothermodynamic challenges, $1 \mathrm{st}$ ARA-Days, Arcachon, July 2006.

[5] M. Sippel, J. Klevanski, Preliminary definition of the supersonic and hypersonic airliner configurations in LAPCAT, AIAA 2006-7984 November 2006.

[6] A. van Foreest, M. Sippel, J. Klevanski, A. Gülhan, B. Esser, Technical background and challenges of the SpaceLiner concept, in: Seventh International Symposium on Launcher Technologies, Barcelona, Spain, April 2-5, 2007.

[7] M. Sippel, Introducing the SpaceLiner vision, in: Seventh International Symposium on Launcher Technologies, Barcelona, Spain, April 2-5, 2007

[8] M. Sippel, A. van Foreest, Latest progress in research on the SpaceLiner high-speed passenger transportation concept, IAC-07D2.7.07, September 2007.

[9] A. van Foreest, M. Sippel, The logistical challenges of the SpaceLiner concept, in: IAA First Symposium on Private Human Access to Space, Arcachon, May 28-30, 2008. 